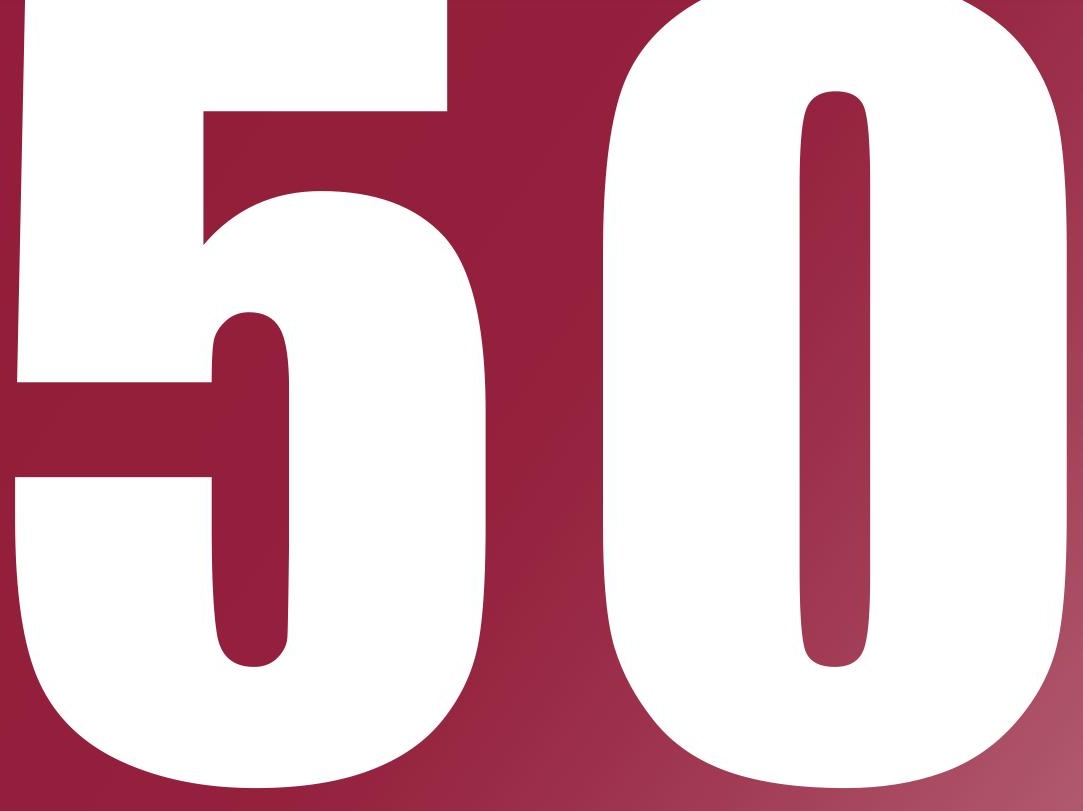

ÁMBITOS

REVISTA

INTERNACIONAL

DE

COMUNICACIÓN

$\mathbf{N}^{\circ} \mathbf{5 0}$

EDICIÓN OTOÑO

2020

ISSN: 1139-1979

E-ISSN: 1988-5733

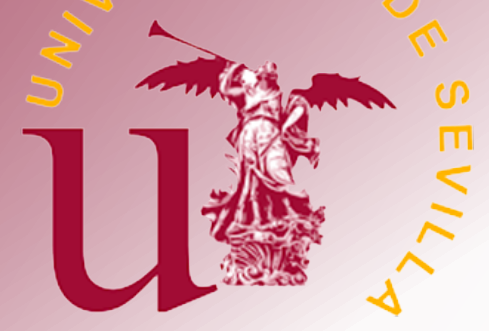




\section{INDICE}

EDITORIAL EDITORIAL

Presentación del Monográfico. Comunicación y juventud. Nuevos medios, representación, recepción y participación en contenidos de entretenimiento e información

Presentation of the monograph. Communication and youth. New media, representation, reception and participation in entertainment and information content.

Juan Francisco Gutiérrez Lozano, Francisco Javier Ruiz del Olmo

7-9

\section{MONOGRÁFICO MONOGRAPH}

El consumo audiovisual de la Generación Z. El predominio del vídeo online sobre la televisión tradicional The audiovisual consumption of Generation $Z$. The predominance of online video over traditional television

La imagen de los jóvenes en las estrategias transmedia de las series de televisión: el caso de Skam España en Instagram

The image of young people in transmedia strategies of TV series: the case of Skam España on Instagram

Sergio Jesús Villén Higueras, Francisco Javier Ruiz del Olmo

La penetración de Netflix en el público español ¿cuestiona el modelo televisivo tradicional?

Does the arrival of Netflix in the Spanish audience challenge the traditional television model?

Javier Bustos Díaz

49-61

Generación Z y consumo de información política: entre la televisión y los nuevos formatos mediáticos Generation $Z$ and consumption of political information: between television and new media formats

Ruth Gómez de Travesedo Rojas, Marta Gil Ramírez

$62-79$

Actualidad y comedia: El éxito de El Intermedio y La Resistencia entre los espectadores jóvenes

Information and comedy: The Success of El Intermedio and La Resistencia for young audiences

Inmaculada Concepción Aguilera García

80-95 
El efecto socializador de articular un espacio de comunidad virtual en el ecosistema del aula

The socializing effect of creating a virtual community space in the classroom environment

Lorea Ariadna Ruiz Gómez, Mónica Hinojosa Becerra, Francisco Javier Ruiz San Miguel

Juventude ciberativista e educação: reflexões sobre um jeito hacker de ser

Cyber activity youth and Education: reflections on a hacker way of being

Carla Azevedo de Aragão, Pietro Matheus Bompet Fontoura Alves, Karina Moreira Menezes

La risa grotesca en la obra de Bob Dylan: análisis de la Bacanal y el Festín Carnavalesco en la trilogía folk-rock eléctrica

Grotesque Laughter in Bob Dylan's Work: Analysis of The Bacchanal and the Carnival Feast in the Electric Folk-rock Trilogy

Jesús Albarrán Ligero

El papel del intertexto en el videojuego. Una partida, mil y una historias

Intertext in video games. A game, thousand and one stories

Rocío Serna-Rodrigo

145-158

\section{ÁmBitos PERSONALES PERSONAL ÁmBITOS}

El auge de Twitch: nuevas ofertas audiovisuales y cambios del consumo televisivo entre la audiencia juvenil The rise of Twitch: New audiovisual offers and the transformation of Television consumption among young audiences

\section{ARTÍCULOS ARTICLES}

La recepción de los medios de comunicación para residentes rusos en la Costa del Sol

Mass media reception by Russian residents on the Costa del Sol

Natalia Meléndez Malavé, José Carlos Pozo García

176-192

La calidad periodística en la cobertura de terremotos: Caso Ecuador

Journalistic quality in earthquake coverage: The case of Ecuador

Juan Pablo Arrobo-Agila, Mendoza María, Ignacio Aguaded

La credibilidad publicitaria en la nueva esfera mediática: los universitarios y los medios

Advertising credibility in the new media sphere: university students and the media 
Arco iris en medios brasileños: percepciones sociales sobre una campaña publicitaria LGBTQIA+

Rainbow in Brazilian media: social perceptions of an LGBTQIA+ advertising campaign

Leonardo Ferreira Batista, José Geraldo de Araújo Ramalho Filho

224-239

Rituales y comunicación política: la toma de posesión de los presidentes autonómicos españoles

Rituals and political communication: the Spanish autonomous Presidents inauguration

Ricardo Domínguez García

240-258

RESEÑAS REVIEWS

Una mirada diferente para hacer periodismo

A different look for making journalism

Guillermo Paredes-Otero

259-261

Periodismo y tecnología: una simbiosis continua

Journalism and technology: a continuous symbiosis

Luisa Graciela Aramburú Moncada

262-265

Una propuesta metodológica para impartir la asignatura de redacción periodística

Journalism and technology: a continuous symbiosis

Noelia Ruiz-Alba

266-268 


\title{
Actualidad y comedia: El éxito de El Intermedio y La Resistencia entre los espectadores jóvenes
}

\author{
Information and comedy: The Success of El Intermedio and La Resistencia \\ for young audiences
}

\author{
Inmaculada Concepción Aguilera García ${ }^{1}$ \\ Universidad de Málaga | Calle León Tolstoi, s/n, Málaga 29010 | España \\ | https://orcid.org/0000-0001-5084-519X | inmaaguilera@uma.es \\ Fechas | Recepción: 12/05/2020 | Aceptación: 05/08/2020 | Publicación final: 15/10/2020
}

\begin{abstract}
Resumen
Los formatos que mezclan contenidos de actualidad con comedia consiguen gran seguimiento entre las audiencias españolas. Estas fórmulas híbridas, que estimulan la reflexión sobre asuntos de interés social y político, así como incorporan nuevas tecnologías que permiten desligar su visualización de la emisión en directo, han hecho que programas como La Resistencia, de David Broncano, o El Intermedio, de El Gran Wyoming, resulten muy atractivos para los jóvenes.
\end{abstract}

Este estudio deriva de una investigación sobre audiencias de infoentretenimiento y la recepción de sus contenidos. En esta etapa, nos preguntamos cuáles son los programas y los presentadores más valorados por las audiencias jóvenes a la hora de informarse de forma distinta sobre la actualidad. Para ello, realizamos una metodología cualitativa en dos fases: primero reunimos un grupo de discusión con espectadores de 18 a 35 años y luego hicimos entrevistas en profundidad a profesionales de dos programas que destacaron las audiencias consultadas, con el fin de contrastar sus reflexiones. De este modo,

\section{Abstract}

The formats that mix information with comedy get a great following among Spanish audiences. These hybrid formulas are usefull to be more critical with social and political issues, as well as the incorporation of new technologies has allowed to detach its visualization from the live broadcast. So programs such as La Resistencia, by David Broncano, or El Intermedio, by El Gran Wyoming, are very attractive to young people. This study parts of an investigation on infotainment audiences and the reception of their contents. At this stage, we wonder which programs and presenters are most valued by young audiences to inform differently about current events. We carried out a qualitative methodology in two phases: firstly, we gathered a discussion group with viewers from 18 to 35 years old and then, we told with professionals from both programs, that highlighted the audiences consulted. In this way, we interviewed the screenwriter Victoria Martín, from La Resistencia, Alberto Casado, collaborator of La Resistencia and former collaborator of Sé lo que hicisteis, and screenwriter Paco Páez and presenter El Gran

Forma de citar:

Aguilera García, I. C. (2020). Actualidad y comedia: El éxito de El Intermedio y La Resistencia entre los espectadores jóvenes. Ámbitos. Revista Internacional de Comunicación 50, pp. 80-95. doi: 10.12795/Ambitos.2020.i50.06 
entrevistamos a la guionista Victoria Martín, de La Resistencia, a Alberto Casado, colaborador de La Resistencia y antiguo colaborador de Sé lo que hicisteis, al guionista Paco Páez y al presentador El Gran Wyoming, de El Intermedio. Tanto audiencias jóvenes como profesionales coincidieron en que el programa que sentó las bases para estas fórmulas fue Sé lo que hicisteis, y destacaron a David Broncano como el presentador favorito de los jóvenes a la hora de ejercer como entrevistador, aun siendo conscientes de su papel como cómico puro.

Palabras clave: televisión, infoentretenimiento, comedia, audiencias.
Wyoming, from El Intermedio. Young audiences and professionals agreed that the program that laid the foundations for these formulas was Sé lo que hicisteis, and they highlighted David Broncano as the favorite presenter for young people as an interviewer, even though they were aware of his role as a comedian.

Keywords: television, infotainment, comedy, audiences.

\section{INTRODUCCIÓN}

Este trabajo deriva de una investigación doctoral en proceso en torno a las audiencias españolas y a la recepción de programas de infoentretenimiento, especialmente aquellos que mezclan informaciones de actualidad con recursos propios de la comedia. Los estudios sobre audiencias de infoentretenimiento no son frecuentes, en cuanto a que también son escasos los dedicados a este género de naturaleza híbrida. La mayoría de los textos enfocados en el infoentretenimiento se centran en análisis de contenido (Simancas y González-Pavón, 2017) y en la categorización de sus diversas manifestaciones en tipologías de programas (Gordillo, 2009), algunos también profundizan en torno a su definición (Krüger, 1988), a su distinción del concepto del infoshow (Luzón y Ferrer, 2008; Salgado, 2010) o a la reflexión sobre el debate que suscita su uso y su utilidad entre los investigadores (Ortells, 2011). La ausencia de manuales para una correcta praxis del infoentretenimiento, a su vez, dificulta su estudio como objeto de reflexión para la recepción, más allá de revisiones en torno a su éxito y seguimiento, cuestiones que aportan investigaciones de naturaleza cuantitativa, apoyadas a menudo en la consulta de datos sobre share. Para profundizar en los motivos del éxito de estos programas, sin embargo, algunos autores destacan la pertinencia de las metodologías cualitativas (Ang, 1985; Morley, 1992), pues, como señala Huertas (1998, como se cita en Martínez-Rolán, 2012) los estudios cuantitativos actuales no aportan datos sobre las preferencias de las audiencias, de ahí nuestro interés por abordar el presente estudio desde este último plano. A su vez, la vulnerabilidad de ciertos sectores de la población, por su naturaleza como nativos digitales, pero carentes todavía de una instrucción en alfabetización mediática (Aguaded, 2012; López-Romero, 2012), convierte a los jóvenes en una fracción del público de la que se requiere hacer distinción.

En esta línea de reflexión, sobre las franjas de edad más jóvenes del público español y sobre su hábito a recurrir a plataformas digitales, difíciles de registrar por los audímetros, lo que es motivado frecuentemente por expectativas ligadas a la participación o al prosumo (Toffler, 1980), nos preguntamos si los intereses de visionado hacia estos programas serían realmente diferentes en función de la edad, y cuáles serían dichos intereses. Para averiguarlo, 
consideramos una investigación en dos fases: En una primera, realizaríamos un grupo de discusión con audiencias jóvenes, con las que reflexionaríamos sobre programas de infoentretenimiento, o sobre aquellos donde se pudiera obtener, para ellas, una doble satisfacción de diversión además de recibir informaciones de actualidad durante el visionado. En la segunda fase, efectuaríamos entrevistas a profesionales de infohumor, que nos servirían para contrastar las reflexiones de los espectadores jóvenes consultados con las de los profesionales de los programas que estos previamente hubiesen destacado.

\subsection{El infohumor como rama destacable del infoentretenimiento español}

El primero en utilizar como tal la palabra infotainment fue Krüger (1988, p.639), entendiéndolo como una "forma mixta" entre información y entretenimiento, y siendo la mayor o menor presencia de una u otra rama en proporción con respecto a la otra la que diferenciaría sus distintas manifestaciones o permitiría establecer clasificaciones entre los diversos programas que se puedan originar, mediante la detección de pautas o estilemas (Martín-Jiménez y Berrocal, 2017) de mutuo acuerdo. Es un concepto, por tanto, que parece depender de la asiduidad y del entendimiento común, también llamado "intuitive understanding" (Reinemann, Stanyer, Scherr y Legnante, 2011; Otto, Glogger y Boukes, 2017), o de su reflexión como fenómeno cultural y social en conjunto (Casero y Marzal, 2011) más que del establecimiento de definiciones cerradas. De hecho, se originan tantos debates entre la comunidad científica a este respecto que algunos autores han bautizado estas fórmulas híbridas como especies "promiscuas" (Soler, 2013). Existe así toda una discusión terminológica en torno a las matizaciones entre los conceptos de infoentretenimiento y de infoshow, en algunos casos el primero como tendencia y el segundo como materialización de la misma (Salgado, 2010) y en otros, como cuestiones bien distintas (Luzón y Ferrer, 2009), hasta el punto de que, hoy por hoy, sigue sin haber consenso entre los investigadores.

Sí que hay ramas o manifestaciones del infoentretenimiento cuyos componentes y elementos llevan a no dudar de lo que se está viendo, caso del infohumor (Gordillo, 2009), una de las ramas o subgéneros del infoentretenimiento que aúna información y comedia. La comedia o el humor, en este sentido, persigue y provoca algo más que el entretenimiento, como es la complicidad con el espectador a través del estímulo a su intelecto (Del Rey-Morató, 2002), apoyándose en hechos actuales muy dados a la crítica o recurriendo a juegos de palabras y a recursos de cierta agresividad, como puede ser la sátira política, que se sirve de figuras, por lo general, polémicas, lo que gusta mucho al público porque "revela los defectos e incongruencias en el discurso de quienes gobiernan" (Carpio, 2008, p. 37). Esta característica lleva a que más de un investigador equipare el infoentretenimiento con el politainment (Nieland, 2008; Sayre y King, 2010; Schultz, 2012; Berrocal, 2017), la mezcla de informaciones políticas con entretenimiento, o, más bien, con humor, como decimos, al estar tan presente el recurso de la sátira o de la caricatura, una tendencia que Silverstone (2007) llamó “Mediápolis".

En el caso de España, se dan además una serie de circunstancias que contribuyen a que estos formatos se encuentren en auge. Por un lado, aunque el primer programa reconocido como infotainment a nivel estatal fue Caiga Quien Caiga (Telecinco, 1996), la crisis socioeconómica y 
política de 2005, que destapó numerosos casos de corrupción, llevó a que la gente se interesase más por la actualidad informativa y por asuntos relacionados con la corrupción, el paro y la evolución de la economía (CIS, 2019), temas que dan mucho juego para la espectacularización, respecto a la chanza y a la broma (Carpio, 2008). A su vez, los artífices y profesionales de los medios también se mostraron interesados por producir fórmulas híbridas que satisficieran sus propias necesidades creativas o de crítica humorística (Salgado, 2010). Pero fue la conjunción de ambas perspectivas la que llevó a que el infoentretenimiento ganase importancia en España, ya que "la información no se limita a los telediarios, sino que se prodiga por otros espacios y formatos televisivos colonizando los programas de entretenimiento" (Rabadán, 2017, p. 67). Es por lo que, aunque el panorama español cuente con programas como El Objetivo, de Ana Pastor, o Lo de Évole, de Jordi Évole, fórmulas muy distintas, pero que aportan a sus audiencias distracción e información, considerando a sus presentadores como "Nuevos Gabilondos" (Capilla, 2015), parece existir además una necesidad añadida entre el público, sobre todo entre los jóvenes, de recibir algo más de las fórmulas híbridas. Algo que satisfaga sus necesidades de interiorizar y de aprender (Mattelard, 2002), de desarrollar su espíritu crítico (Del Rey-Morató, 2002) y de fomentar sus necesidades de participación o de movilización ciudadana (Antón, Marcos, 2016) para alejarles del contenido informativo serio y los acerque al entretenimiento (Berrocal, Martín-Jiménez y Gil-Torres, 2017).

\subsection{El infohumor y los jóvenes, necesidad de alfabetización mediática}

Los infoshows españoles actuales consiguen atraer a diferentes generaciones de audiencias, observándose algunas diferencias entre ellas, ya que los jóvenes tienden a ser receptores pasivos de Internet (Fernández-Planells y Figueras-Maz, 2012) mientras que "los perfiles de más edad, especialmente jubilados, y de otros ámbitos, difícilmente conocen las posibilidades efectivas ni acceden a las segundas pantallas o a los medios interactivos" (Alonso, Broullón y Lamuedra, 2016, p. 188). Por una parte, la tecnología en diferido y los soportes móviles contribuyen a desligar del directo y a facilitar el visionado de programas en cualquier lugar, lo que supone una imprevisibilidad de la recepción televisiva (Wilson, 2011), y de muy diversas formas, como pueda ser simultáneamente al tiempo que se consume otro producto audiovisual en un televisor, lo que se denomina consumo multipantalla (Teso y Piñuel, 2015), la "acción de leer, comentar y compartir información sobre contenido televisivo en segundas pantallas, de dispositivos de consumo secundarios" (Coromina, Delgado, Prado y García-Muñoz, 2020, p. 474), convirtiendo de este modo a los potenciales espectadores en "audiencias híbridas" (Quintas y González-Neira, 2016). Por otra parte, esta realidad, añadida al recurso de las redes sociales, ha permitido una participación mucho más activa de las audiencias, ganándose con ello el calificativo de "ciudadanos telespectadores" (Rosique, 2013), y canales como \#0, que apuestan por formatos de humor, "exponen sus contenidos de pago, aunque en pequeñas dosis y desde narrativas transmedia, a través de Instagram, como una estrategia de engagement" (Gascón, 2020, p. 191). Sin embargo, este concepto de mayores oportunidades de participación enlazaría con el "prosumo" de Toffler (1980), que venía a señalar esa doble función del espectador de querer consumir y producir contenidos al mismo tiempo, o, sencillamente, de interactuar con otros espectadores, y no tanto como una participación como la que estaría 
asociada al concepto del erróneamente llamado "periodismo ciudadano", y más correcta "comunicación social ciudadana" (Antón, 2016). Como señalan Dhoest y Simon (2016, como se cita en Lacalle y Gómez-Morales, 2017, p. 198), esta realidad supone una nueva preocupación para los investigadores, pues "lamentan que una buena parte de la reflexión sobre la televisión y su futuro se centre en los cambios industriales y tecnológicos sin comprobar empíricamente la adopción efectiva de las nuevas posibilidades que implican para la audiencia".

Estudios como el de Lacalle (2013) o el de Giglietto y Selva (2014) confirman que Twitter, así como otras redes sociales, se emplea más para expresar las opiniones de los espectadores sobre el programa que comentarios autorreflexivos, informativos o emotivos, sin embargo, el recurso a la sátira política (Carpio, 2008) supone un estímulo para las audiencias (Del Rey-Morató, 2002). Ello origina en los espectadores una expectativa de formar parte de esa crítica cómica o, en su lugar, de enfatizarla para promover el debate público o la movilización ciudadana, "posible gracias a la producción de información desde la ciudadanía y a la autorreplicación viral del mensaje, característica básica en la comunicación de informaciones a través de las redes sociales" (Antón y Marcos, 2016, p. 103). Pues, al poder apreciar en las redes directamente las opiniones y críticas de las audiencias, estas adquieren un nuevo carácter como fuente informativa de "primer orden" (Ortells, 2015) para los artífices y las cadenas, convirtiendo a la televisión en el "reino de los cualquiera" (Prado, 1999, p.201). Esto, a su vez, supone "un dualismo de espacios y de tiempos que establece unos biorritmos sociales especialmente en los menores" (Marta y Gabelas, 2008, p. 110), lo que convierte a estos últimos en un sector vulnerable.

Los estudios en alfabetización mediática insisten en la importancia de que los ciudadanos reciban desde niños una educación en consumo de medios desde el mismo núcleo familiar "en tanto que el consumo principal se realiza dentro de los hogares", además de existir "una corresponsabilidad desde otros sectores como la escuela, los propios medios de comunicación y también por parte de la Administración pública" (López-Romero, 2012, p. 86). Siendo los actuales adolescentes y jóvenes una generación nacida además en la tecnología y en el consumo audiovisual a través de Internet, donde "creadores muy activos como los youtubers se han convertido en líderes de opinión y fenómenos masivos" (Rodríguez-Breijo, Gallardo-Camacho y Sierra-Sánchez, 2018, p.1048), parece necesaria una mayor concienciación sobre los contenidos que se estén visualizando, sobre todo en formatos tan volubles como los que se pueden dar en el infohumor español.

\section{OBJETIVOS Y PREGUNTAS DE INVESTIGACIÓN}

Teniendo en cuenta que los estudios sobre infoentretenimiento se centran en análisis de contenido (Gascón, 2016), y que los que persiguen el punto de vista de los espectadores se ciñen a conceptos de calidad (Guerrero y Etayo, 2015), o de medición de audiencia, lo que sería más propio de la percepción que de la recepción, comprendimos que una metodología cualitativa resultaría más adecuada para profundizar en las motivaciones de las audiencias, pues "si se quiere reconstruir analíticamente la calidad de los programas de televisión atendiendo a los gustos de la audiencia, es necesario comenzar interrogando con detenimiento al complejo 
proceso que se activa en la relación espectador-programa, para dar cuenta de la generación de placeres o frustraciones y de los elementos que ingresan en la experiencia" (Berti, 2000, p. 2).

De este modo, con este estudio pretendimos profundizar en las audiencias de infoentretenimiento jóvenes españolas, con el objetivo de averiguar si estas se distinguían de las audiencias de más edad en cuanto a preferencias, hábitos e intereses de consumo. Además, nos preguntamos cuáles serían los programas que encontrarían más productivos para obtener diversión e información al mismo tiempo y cuáles serían los conductores que más les satisfacen a este respecto.

\section{METOdOLOGÍA}

Para abordar la investigación, planteamos una metodología de naturaleza cualitativa en dos fases. Para recoger el punto de vista de la audiencia joven, recurriríamos a la herramienta del grupo de discusión, ya que "se considera la principal técnica cualitativa para la recogida de información" (Suárez-Ortega, 2005, p. 17), pues "solo la interacción grupal permite acariciar aquella información que se constituye en la medición colectiva" (Llopis Goig, 2004, p. 28), además de que es una herramienta de estudio que aporta ciertas ventajas, "como puedan ser la posibilidad de modificar preguntas, seguir el hilo de respuestas interesantes, investigar las motivaciones, así como acceder a valiosísima información no verbal que emiten los sujetos" (Alonso, Broullón y Lamuedra, 2016, p. 183). De este modo, como primera fase, realizamos un grupo de discusión con audiencias jóvenes, con las que reflexionamos sobre programas de infoentretenimiento, o aquellos en donde se pudiera obtener, a su juicio, una doble satisfacción de recibir informaciones de actualidad, además de divertirse durante el visionado. Este grupo de discusión estuvo compuesto por tres hombres y dos mujeres, de edades comprendidas entre 18 y 35 años.

Para registrar el punto de vista profesional, utilizaríamos la herramienta de la entrevista en profundidad, sirviéndonos del método de Gorden (1987) para recoger también el contexto donde se plantea la entrevista. A su vez, puesto que es la audiencia joven el objeto último de la investigación, partiríamos de las reflexiones surgidas en el grupo de discusión para plantear el cuestionario dirigido a los artífices encuestados, a partir del sistema de derivación de Wengraf (2001) que emplea las preguntas de investigación, en este caso originadas en el grupo de discusión, para establecer las preguntas de entrevista que se realizarían a los profesionales. Así pues, en la segunda fase, efectuamos entrevistas a profesionales de infohumor, que nos servirían para contrastar las reflexiones de los espectadores jóvenes consultados con los profesionales de los programas que estos previamente hubiesen destacado, en este caso, EI Intermedio y La Resistencia. Y las personalidades escogidas para la muestra fueron: Victoria Martín, guionista de La Resistencia, Alberto Casado, colaborador de La Resistencia y antiguo colaborador de Sé lo que hicisteis, Paco Páez, guionista de El Intermedio, y El Gran Wyoming, presentador de El Intermedio.

Teniendo en cuenta que para el planteamiento y la elaboración de las entrevistas seguimos el esquema de derivación de Wengraf (2001), para la selección de estos dos programas dimos 
prioridad a la reflexión de las audiencias consultadas en el grupo de discusión, que consideraron La Resistencia como programa destacable. Si nos hubiésemos ceñido a categorizaciones establecidas (Gordillo, 2009), La Resistencia sería un programa de entretenimiento más que de infotainment, pero insistimos en que fueron los espectadores jóvenes consultados quiénes consideraron este programa ejemplo de espacio del que podían obtener información útil al tiempo que diversión.

\section{RESULTADOS}

Tras realizar los distintos encuentros con los cuatro profesionales de los programas de interés, y contrastar sus reflexiones con los comentarios recogidos en el grupo de discusión previo, obtuvimos los siguientes resultados en base a las preguntas de investigación:

-A la hora de recibir información y entretenimiento al mismo tiempo, los espectadores jóvenes destacaron dos programas: La Resistencia y El Intermedio. La Resistencia, porque afirmaron disfrutar de las entrevistas a personajes de la actualidad más que con ningún otro programa donde pudiesen acudir dichos personajes. Además de que obtenían de ellos una información, o una perspectiva, dijeron, muy distinta. Esta opinión fue opuesta a los artífices de La Resistencia, que reconocían trabajar en un programa de naturaleza completamente de entretenimiento, y que no se proponían informar con sus contenidos. Con El Intermedio esta opinión fue más moderada por ambas partes, pues tanto audiencias como profesionales consideran que EI Intermedio sí es un programa donde se muestran informaciones al tiempo que se hace humor.

Ejemplos:

"Yo lo veía mucho antes, prácticamente todos los días, en vez de ver noticias o lo que sea me ponía El Intermedio, porque me enteraba de lo que sea más o menos y me reía un rato. Pero ya desde hace tiempo creo me están ganando [...] lo que son programas por Internet, descargármelos, sin anuncios, por ejemplo, el programa de David Broncano" (espectadora 2, mujer, 22 años).

"La gente busca la información en otras vías, no pretende que David Broncano le dé una información objetiva de lo que está pasando [...] Yo creo que es un referente precisamente por eso, porque ofrece otras posibilidades, otros temas de conversación, otros debates que no se están tratando, que no se tratarían en un informativo, y yo creo que eso es lo que la gente agradece, tener la oportunidad, con un programa como La Resistencia, que no tengan que estar pensando, sino que puedan estar simplemente disfrutando, riéndose y olvidándose un poco de los problemas, que al final es para lo que sirve la comedia" (Victoria Martín, guionista de La Resistencia).

"Si algo gusta, no gusta porque sea periodístico. O sea, Broncano entrevista a gente y desde una visión cero periodística y que creo que una entrevista para ser interesante no tiene por qué ser periodística. Simplemente, si entretiene y a la gente le mola, ya está. Luego puede llegar Gabilondo y hacer un programa de entrevista brutal y molar mucho, pero que es compatible" (Alberto Casado, colaborador de La Resistencia). 
"El entretenimiento es lo que lo que hace que sea fácil de ver y se disfrute, pero siempre partiendo desde la información" (Paco Páez, guionista de El Intermedio).

-Los espectadores jóvenes apuntan a que estos programas atraen por su componente crítico y polémico. La intención de provocación es reconocida por los artífices de ambos programas, no obstante, estos matizan que no pretenden sentar doctrinas de ningún tipo, a pesar de que los espectadores jóvenes consultados tuvieron bastante que decir al respecto, entre otras cuestiones, que muchos temas que se manifiestan en ambos programas sentaban debate en la ciudadanía.

Ejemplos:

"Yo por ejemplo he estado dos veces delante de un juez, y ha sido ahora, a partir de los sesenta años. Te puedo asegurar que yo era bastante más radical [...] A mí me gustaría que este programa realmente sirviera para algo, porque se hace con mucha honestidad, independientemente de que nos equivoquemos, porque uno está en el derecho a equivocarse, pero mentir es otra cuestión. Entonces este programa está hecho con mucha honestidad, y ojalá esto que denunciamos sirviera para algo. Pero no lo veo yo que vayamos a salvar el mundo con esto. Me gustaría" (Wyoming, presentador de El Intermedio).

"Yo quería saber si realmente se les condenó [a Dani Mateo y a Wyoming], porque a lo mejor este tipo de acusación algunas veces hacen denuncia para que se cree la polémica, se hable del tema, aunque saben que en base a derecho no tiene recorrido. Entonces, si el juicio no pasó de determinada fase..." (espectador 5, hombre, 30 años).

“Pero ya el que ese punto de que se lleve hasta juicio, ya me parece demasiado. Aunque tú digas, venga, vamos a denunciar para crear polémica y levantar ampollas, pero ya es que, que se le haga caso a esa denuncia y se lleve a un juzgado de instrucción" (espectador 1, hombre, 28 años).

"La Resistencia es un programa de entretenimiento puro y duro. O sea, de hecho, además, una de las premisas básicas del programa es que mientras sea gracioso, puede, o sea, puede entrar, y eliminar completamente cualquier cosa, cualquier atisbo de moraleja en los chistes que hacemos, o de crítica, que, si a veces la hay, estupendo. Yo creo que el humor, por lo menos el que hago yo, para mí, es muy importante la crítica" (Victoria Martín, guionista de La Resistencia).

-A pesar de que varios de los espectadores consultados se declararon no simpatizantes de Wyoming, todos coincidieron en que es un hombre estimado por la sociedad en general e incluso un líder de opinión. El único que no lo veía así fue el propio Wyoming.

Ejemplos:

"Parece ser un tío [Wyoming] que usa mucho el sarcasmo, pegando muchos, muchos pullazos y no sé, las cosas que dice, y denuncia, me hacen gracia, porque las dice con cierta, con sarcasmo y pegando. Me gusta, me gusta. A mí realmente me gusta, pero no lo suelo ver con regularidad" (espectador 1, hombre, 28 años). 
"Yo conozco al Gran Wyoming, he tenido la fortuna de verlo hacer el programa un par de veces y a mí personalmente, cero gracia. Pero no por el contenido del chiste, sino por la forma en que hila. Un humor muy básico, no sé. No es por el contenido, eh, sino la forma de hilar los chistes me parece muy predecible, ¿no? Pero ya te he dicho, lo he visto nada más que un par de veces y la verdad es que no me llamó mucho la atención, la verdad" (espectador 4, hombre, 29 años).

“Un tío inteligente, ¿no? No sé. La verdad es que no sé mucho de él tampoco. Sé que tiene su carrera de medicina y tal, que le va la política, de izquierdas, simpatizo también en ese sentido con él, pero la verdad es que no conozco yo mucho tampoco a ese hombre, qué hace, qué no hace, nada más que lo conozco por El Intermedio, entonces" (espectadora 2, mujer, 22 años).

"Es un tío muy inteligente, un tío que transmite, que sabe comunicar bien, que lleva muchos años en pantalla también, es conocido, tiene, digamos, mucha gente confía en su criterio. Por eso es un líder de opinión" (Paco Páez, guionista de El Intermedio).

“Ojalá no lo sea. No, no soy líder de opinión. Lo que pasa es que este programa lleva 14 años dando una información en un sentido, que tiene línea editorial, entonces, de alguna manera, ha batido récords. [...] Yo soy el presentador. Es decir, que yo no estoy transmitiendo ninguna doctrina de la que yo me haría responsable [...] pero la opinión negativa viene siempre del mismo sentido, y hasta cierto sentido me siento muy orgulloso de que eso me ocurría hace treinta años y de no haber cambiado tanto, de haber sido coherente con lo que fui y con lo que espero ser en un futuro" (Wyoming, presentador de El Intermedio).

-El éxito de Wyoming se achacaba a su propia personalidad y talento único, y a la costumbre de verlo desde Caiga Quien Caiga, aunque muchos espectadores eran niños y apenas lo recuerdan en aquella época.

Ejemplos:

“El Gran Wyoming, sí, pero no por este programa, sino por otro que había cuando yo era pequeña, no me acuerdo [...] ¿Caiga Quien Caiga, era? Pues de ese sí me suena porque era más pequeña y veía más la tele y sé que es por eso, por ese programa" (espectadora 3, mujer, 29 años).

"Importa que el programa mole. Luego también puede haber gente que sea muy buena, como el tema de Wyoming. Si fuera malo no estaría bien, pero obviamente hay gente que tienen más tirón que otros" (Alberto Casado, colaborador de La Resistencia).

-Con respecto a David Broncano, aunque solo una de las espectadoras se declaró fiel seguidora, los otros cuatro también reconocieron el gran impacto que tiene este presentador concreto entre la población joven. La guionista y el colaborador de La Resistencia certificaron el éxito del programa argumentando que se debía por completo a que los jóvenes simpatizan mucho con la apariencia y el estilo de Broncano.

Ejemplo:

"Tiene esa presencia de chaval distendido, que dice lo que se le pasa por la mente en ese momento. Creo que el valor de David, como cómico, es la improvisación y la naturalidad. [...] Y 
yo creo que eso a la gente le gusta mucho, porque a la gente cada vez le chirría más las cosas que parecen estar muy guionizadas. Y David es eso, joven, se atreve a decir cualquier cosa. Entonces, los chicos jóvenes se sienten súper identificados con él y les encanta" (Victoria Martín, guionista de La Resistencia).

-Tanto espectadores jóvenes como los artífices de La Resistencia afirmaron que el programa que sentó las bases para el éxito de los programas actuales fue Sé lo que hicisteis, y que Broncano imitaba bastante la línea de aquel antiguo programa. Los jóvenes lo recuerdan con nostalgia a pesar de que critican el papel cómico que hacía Patricia Conde respecto a su condición de mujer, aunque la guionista Victoria Martín se mostró más preocupada por las líneas de los programas actuales.

Ejemplos:

"Al final te informabas en verdad. Te informabas de alguna manera" (espectador 1, hombre, 28 años).

"Yo voy a plantearlo desde otra perspectiva. A mí, el tema de, cómo se llama, Sé lo que hicisteis, ¿no?, a mí, yo lo veía, ¿vale?, pero muy poco, y no me interesaba porque había como una perspectiva cómica de presentador y chica tonta o algo así, que eso no me llamaba nada la atención" (espectador 4, hombre, 29 años).

“Pero a mí [Patricia Conde] me resultaba muy natural. Había veces que sí hacía un papel de chica tonta, tontísima. [...] Se le cogía cariño por eso, pero es verdad que era un contraste muy, muy feo. Presentador inteligente, chica tonta" (espectadora 2, mujer, 22 años).

"El público de Sé lo que hicisteis creo que era más parecido al de La Resistencia. Como gente joven con ganas de ver cosas más ahí un poco en tu lenguaje, sacar cosas del programa que luego dices con tus amigos. Creo que era más parecido a ese público" (Alberto Casado, colaborador de La Resistencia).

-Tanto espectadores como artífices reconocen que el carácter cómico de estos programas y su formato desenfadado, dividido en secciones, facilita su difusión a través de redes sociales, lo que a su vez contribuye a que se puedan ver desligados del directo. Aunque, a este respecto, también señalaron su comodidad para otro tipo de programas o espacios.

Ejemplos:

“De La Resistencia, el público es mayoritariamente hombres, entre 18 y 25 años. Básicamente. O sea, más o menos ese es el target del programa, gente muy joven. Se consume mucho más $L a$ Resistencia a través de YouTube que a través de la propia plataforma de Moviestar, porque muchísimos chavales no tienen Moviestar" (Victoria Martín, guionista de La Resistencia).

“Esta última vez cuando trajimos lo de Twitter, las críticas que le hacen en Twitter, nos costaron un poco de trabajo porque había muchos comentarios positivos. O sea, a mí me sorprendió porque dije 'joder, en realidad la gente quiere a Wyoming más de lo que yo pensaba', pues tuvimos que escarbar un poquito para encontrar comentarios negativos" (Paco Páez, guionista 
de El Intermedio).

"Aunque me suelo más informar de las noticias por Facebook o lo social, Twitter, no sé, y ya voy contrastando, voy buscando si una cosa es cierta o no, porque no te puedes tragar todo lo que ves tampoco, básicamente. [...] A ver, yo no veo el programa [El Intermedio] con regularidad, pero, claro, a veces paso tiempo en Facebook, y suelen colgar partes del programa" (espectador $1, \mathrm{H}, 28$ años)

"Porque estos programas muchas veces hacen recortes pequeñitos de la frase más chula, para que la gente las comparta" (espectador 5, hombre, 30 años).

“Le pongo cara porque en el Facebook sí han compartido algún vídeo de Jordi Évole y sé que es él” (espectador 3, M, 29 años).

\subsection{Una distinción interesante: David Broncano y Jordi Évole}

De entre todas las reflexiones contrastadas, encontramos destacable que los jóvenes consultados señalaron admirar también a Jordi Évole, antiguo presentador de Salvados (laSexta, 2008) y actual de Lo de Évole (laSexta, 2020), pero siempre como comunicador informativo, pues con este presentador sí demostraron ser conscientes de que su estilo pertenece al género periodístico, cosa que no les ocurría con David Broncano, al cual no asociaban su profesión puramente cómica.

"Sí, porque me parece interesante [Salvados] y porque, ¿cómo te digo?, es un programa que mucha gente ve y el tema que se trata al final está encima de la mesa en los debates mucho tiempo esa semana, esa otra semana, y para hablar con la gente es interesante. [...] Pero para mí también es que fue muy importante, creo, que en aquel momento este tío [Jordi Évole] empezaba a ser como una estrella, y había un grupo de gente que lo veía 'este tío es que es Dios', 'este, lo que él diga es lo que yo me creo', y me parece que él tuvo un poco la humildad de decir 'no te creas ni lo que yo digo' (espectador 5, hombre, 30 años).

"Yo lo he visto un par de veces [Jordi Évole] y las veces que lo he visto me ha gustado mucho el contenido, un tío muy crítico y que va al pueblo, y la verdad es que me parece que el tío sea tan directo y que, para mí, dice verdades como puños, me atrae. No lo veo, ya lo he dicho, de forma muy reiterada, sino simplemente lo habré visto un par de veces en toda mi vida, pero lo poco que vi, consiguió engancharme un poco a la televisión" (espectador 4, hombre, 29 años).

\section{CONCLUSIONES}

En base a las preguntas que formulamos, y ciñéndonos a los testimonios recogidos con ambas experiencias, podemos determinar las siguientes conclusiones:

Los programas que más valoraron los espectadores jóvenes consultados fueron La Resistencia y El Intermedio, porque aúnan, según ellos, temas de actualidad y comedia. Es decir, los jóvenes, por encima del entretenimiento, valoran el humor, sobre todo si es crítico, e incluso agresivo, de ahí que un programa como La Resistencia, que en principio es categóricamente de entretenimiento puro, pueda ser considerado de infohumor a ojos de su audiencia. Esta realidad 
es conocida por los artífices de ambos programas, quienes son conscientes de que ser polémicos les beneficia, y coinciden en que el humor debe ser crítico para funcionar.

Los jóvenes consultados tienen a David Broncano como presentador referente para recibir contenidos de actualidad de forma humorística, pues no se paran a pensar que dicho presentador pertenezca al ámbito de la comedia, sino que sus entrevistas les sirven para documentarse de personalidades o de asuntos de actualidad al mismo tiempo que se divierten. Jordi Évole es también respetado como profesional, pero de él no aspiran a recibir entretenimiento porque sí se le tiene como periodista en el imaginario colectivo, por muy interesantes que sean sus reportajes o el debate que susciten. No se espera, por tanto, de Jordi Évole esa doble vertiente informativa-humorística que sí esperan de David Broncano. A Wyoming lo aprecian, pero más por su trayectoria y consolidación, así como por la línea ideológica progresista de los programas en los que participa o ha participado, pero es David Broncano con el que empatizan más por su apariencia, aptitudes y actitud. La Resistencia, de este modo, es para ellos el programa de referencia, y Sé lo que hicisteis, el que sentó las bases.

El seguimiento de estos programas, o de ciertos contenidos de los mismos, por los jóvenes se realiza sobre todo a través de redes sociales y plataformas de Internet 0 de narrativas transmedia (Gascón, 2020) y no tanto por el directo, además de que el simple gesto de compartir dichos contenidos les sirve para sentirse partícipes y para originar debates, pues "la práctica de retuitear sugiere que al menos una parte de la audiencia desea integrarse en una comunidad más amplia" (Lacalle y Gómez-Morales, 2017, p. 201). Sin embargo, vemos que nuestras reflexiones coinciden con las conclusiones del estudio planteado por Coromina, Delgado, Prado y García-Muñoz (2020, p. 480) sobre audiencia social en Twitter, por afirmar que el infoshow es el género que más recurre a la publicación de contenidos en Twitter, pero que ello "no necesariamente implica una mayor interacción con los usuarios de la plataforma", diferente a otro tipo de espacios. Por otra parte, los resultados expuestos matizan el propósito de movilización ciudadana, algo que los espectadores jóvenes valoran muy positivamente, aunque no fuese la intención original de los artífices del programa. Ello, no obstante, supone ciertas contradicciones en los discursos que dieron los profesionales entrevistados a este respecto en cuanto a asegurar que no pretendían, ni debían, transmitir ideologías o doctrinas con sus contenidos, pero que, sin embargo, recurrían a la crítica política a través del humor porque la consideraban necesaria como responsabilidad social y profesional.

Comprendemos entonces que este estudio es limitado y que podemos profundizar mucho más, por ejemplo, realizando más grupos de discusión, o estableciendo una relación con metodologías cuantitativas que abarquen un mayor número de espectadores para confirmar si, efectivamente, La Resistencia y El Intermedio son los programas más valorados por los jóvenes españoles porque les aporten esta doble vertiente de comedia y actualidad. Del mismo modo, convendría ampliar el espectro de programas y espacios que los jóvenes consumen en Internet de los que puedan obtener esta misma doble satisfacción. Estudios como el de Rodríguez-Breijo, Gallardo-Camacho y Sierra-Sánchez (2018) concluyen que quizá sea prematuro afirmar que exista un autoabastecimiento informativo (Castells, 2010), porque la mayoría de los vídeos 
ligados al politainment que analizaron de la plataforma YouTube carecían de pluralidad de puntos de vista y de fuentes consultadas. Sin embargo, dado el uso y la frecuencia que hacen los jóvenes de estas plataformas sería oportuno ahondar en los significados que les dan a estas últimas para responder a unas necesidades informativas y lúdicas de las que, probablemente, las audiencias no sean conscientes, partiendo de la base de que se tiende a consumir más contenido del pretendido (Etayo y Bayo, 2014).

\section{Referencias}

Aguaded, J. I. (2012): La educomunicación. Una apuesta de mañana, necesaria para hoy. En R. García-Ruíz, A. Ramírez-García y M. M. Rodríguez-Rosell (2014). Educación en alfabetización mediática para una nueva ciudadanía prosumidora. Comunicar, 22(43), 15-24. doi: 10.3916/C43-2014-01

Alonso, E., Broullón, M. y Lamuedra, M. M. (2016). Análisis empírico de las dinámicas de remediación entre televisión e internet en España: discursos de receptores. Revista Latina de Comunicación Social, 71, 179-196.

Ang, I. (1987). On the politics of empirical audience studies. En Morley, D. (1992). Television, audiences and cultural studies. London and New York: Routledge. doi: 10.4185/RLCS-2016-1090

Antón, M. (2016). La comunicación social ciudadana. Análisis del activismo político on line en el periodismo de protesta. Telos, 102, 98-108. Recuperado de https://telos.fundaciontelefonica.com/archivo/numero102/

Berrocal, S., Martín-Jiménez, V. y Gil-Torres, A. (2017). Líderes políticos en YouTube: Información y politainment en las elecciones generales de 2016 (26J) en España. El profesional de la información, 5(26), 937-946. doi: 10.3145/epi.2017.sep.15

Berti, H. (2000). La experiencia del espectador: una propuesta teórica para investigar la calidad de los programas de televisión. Revista Latina de Comunicación Social, 34. Recuperado de https://dialnet.unirioja.es/servlet/articulo?codigo $=969553$

Capilla, M. (2015). Los nuevos 'gabilondos': Los periodistas que crean opinión y marcan tendencia electoral. El siglo de Europa, 1103, 31-38. Recuperado de http://www. elsiglodeuropa.es/siglo/historico/2015/1103/1103Dossier.pdf

Carpio, J. A. (2008). El humor en los medios de comunicación: estudio de Los Guiñoles y sus efectos en las opiniones políticas. (Tesis doctoral). Universidad Pontificia de Salamanca, España.

Casero, A. y Marzal, J. (2011). Periodismo en televisión: Nuevos horizontes, nuevas tendencias. Zamora: Comunicación Social Ediciones y Publicaciones.

CIS (2007-2019) Centro de Investigaciones Sociológicas, Percepción de los principales problemas de España. Recuperado de http://www.cis.es/cis/export/sites/default/Archivos/Indicadores/documentos html/TresProblemas.html

Coromina, O., Delgado, M., Prado, E. y García-Muñoz, N. (2020): Estrategias de activación de la audiencia social en Twitter de los programas más populares de la televisión generalista en Europa. Estudios sobre el Mensaje Periodístico, 26(2), 473-482. doi: 10.5209/esmp.67727

Del Rey-Morató, J. (2002). La risa, una actividad de la inteligencia. CIC: Cuadernos de información y comunicación, 7, 329-350. Recuperado de https://revistas.ucm.es/index.php/CIYC/article/view/CIYC0202110329A/7349

Dhoest, A. y Simon, N. (2016). Still 'Watching' TV? The Consumption of TV Fiction by Engaged Audiences. En M. R. Lacalle y B. M. Gómez-Morales (2017). La recepción televisiva española en la era multipantalla, Comunicación y sociedad, 30, 197-216. doi: 10.32870/cys.v0i30.6135 
Etayo, C. y Bayo, A. (2014). El sobreconsumo y el infraconsumo de televisión en España. Anàlisi, 51, 1-15. doi: 10.7238/a.v0i51.2004.

Fernández-Planells, A. y Figueras-Maz, M. (2012). La televisión e Internet hoy: diferentes roles. Usos y consumos en el tiempo libre de jóvenes de Barcelona y Lima. Icono14, 10(3), 176-201. doi: 10.7195/ri14.v10i3.200

Gascón, P. (2016). Claves del éxito de una década televisiva: estudios de caso El hormiguero y $\mathrm{El}$ intermedio. Revista faro, 1(23), 42-71. Recuperado de http://revistafaro.cl/index.php/Faro/article/view/459

Gascón, P. (2020). El infoentretenimiento en la televisión de pago, Movistart y el canal \#0. El uso transmedia de sus contenidos de humor. Ámbitos. Revista Internacional de Comunicación, 49, 177-196. doi:10.12795/Ambitos.2020.i49.11

Giglietto, F. y Selva, D. (2014). Second Screen and Participation: A Content Analysis on a Full Season Dataset of Tweets. Journal of Communication, 64(2), 260-277. doi: 10.1111/jcom.12085

Gorden, R. (1987). Interviewing. Strategy, techniques and tactics, Homewood-Illinois: Dorsey Press.

Gordillo, I. (2009). La hipertelevisión: géneros y formatos. Quito-Ecuador: Ciespal.

Guerrero E. y Etayo, C. (2015). Percepción de calidad de los programas de entretenimiento televisivos en España: influencia de los valores de producción. El profesional de la información, 4(3), 256-264. doi: 10.3145/epi.2015.may.05

Ibáñez, J. (1979). Más allá der la sociología. El grupo de discusión: técnica y crítica. En R. Llopis Goig (2004). Grupos de discusión. Manual de aplicación a la investigación social, comercial y comunicativa. Madrid: ESIC.

Krüger, U. M. (1988). Infos-Infotainment-Entertainment, Media Perspektiven, 10, 637-664.

Lacalle, C. (2013). Jóvenes y ficción televisiva. Construcción de identidad y transmedialidad. Barcelona: UOCPress.

Lacalle, M. R. y Gómez-Morales, B. M. (2017). La recepción televisiva española en la era multipantalla, Comunicación y sociedad, 30, 197-216. doi: 10.32870/cys.v0i30.6135

Llopis Goig, R. (2004). Grupos de discusión. Manual de aplicación a la investigación social, comercial y comunicativa. Madrid: ESIC.

López-Romero, L. (2012). La alfabetización mediática a debate. Planteamiento didáctico de una dinámica de grupo en el ámbito universitario. Icono14, 10(3), 85-99. doi: 10.7195/ri14.v10i3.184

Luzón, V. y Ferrer, I. (2008). Espectáculo informativo en noticias de sociedad: el caso de Madeleine McCann. Trípodos, 22, 137-148. Recuperado de https://www.raco.cat/index.php/Tripodos/article/view/76531/97284

Marta, C. y Gabelas, J. A. (2008). La familia en el escenario de las multipantallas. Doxa Comunicación, 7, 109-125. Recuperado de http://opendata.dspace.ceu.es/handle/10637/5916

Martínez-Rolán, L. X. (2012). La audiencia televisiva. Una aproximación teórica a la eficiencia y legitimidad de las audiencias. Revista de Ciencias de la Información, 29, 10-21. Recuperado de https://dialnet.unirioja.es/servlet/articulo?codigo=5680490

Martín-Jiménez, V. y Berrocal, S. (2017). Innovación y consolidación del «infoentretenimiento» político: una perspectiva histórica. Historia y comunicación social, 22(1), 191-206. doi: $10.5209 /$ HICS.55908 
Mattelard, A. (2002). La nueva comunicación. En M. Redondo y E. Campos-Domínguez (2014). Implicaciones éticas del infoentretenimiento televisivo, Comunicació: Revista de Recerca $i$ dÀnàlisi, 32(1), 73-89. doi: 10.2436/20.3008.01.130

Ortells, S. (2011). El infoentretenimiento en el periodismo audiovisual. La transformación del género informativo en televisión (Tesis doctoral). Universidad Jaume I de Castellón, Valencia.

Ortells, S. (2015). Los magazines de actualidad basados en el infoentretenimiento: nuevos rasgos del lenguaje audiovisual en el periodismo televisivo. Signo y Pensamiento, 66(34), 44-61. doi:10.11144/Javeriana.syp34-66.mabi

Otto, L., Glogger, I. y Boukes, M. (2016). The softening of journalistic political communication: A comprehensive framework model of sensationalism, soft news, infotainment, and tabloidization. Communication Theory, 27(2), 136-155. doi: 10.1111/comt.12102

Prado, E. (1999). El fenómeno Infoshow: La realidad está ahí fuera, En S. Ortells (2015b). Los nuevos actores de la información televisiva: ciudadanos y periodistas como protagonistas del infoentretenimiento. Estudios sobre el mensaje periodístico, 1(21), 491-508. doi: 10.5209/rev_ESMP.2015.v21.n1.49107

Quintas, N., y González-Neira, A. (2016). Consumo televisivo y su medición en España: camino hacia las audiencias híbridas. El profesional de la información, 25(3), 376-383. doi: 10.3145/epi.2016.may.07

Rabadán, P. J. (2017). Tendencias de comunicación política en televisión en la campaña electoral del 26J de 2016 en España. Comunicación y hombre, 13, pp. 67-83. Recuperado de https://www.redalyc.org/pdf/1294/129449617004.pdf

Reinemann, C., Stanyer, J., Scherr, S. y Legnante, G. (2012). Hard and soft news: A review of concepts, operationalizations and key findings. Journalism, 13(2), 221-239. doi: $10.1177 / 1464884911427803$

Rodríguez-Breijo, V, Gallardo-Camacho, J. y Sierra-Sánchez, J. (2018): Información política en los vídeos que son tendencia en YouTube España. El profesional de la información, 27(5), 1041-1049. doi: 10.3145/epi.2018.sep.08

Rosique, G. (2013). El estudio de la recepción televisiva desde la perspectiva de la ciudadanía organizada. Historia y comunicación social, 18(3), 213-224. doi: 10.5209/rev_HICS.2013.v18.44323

Salgado, A. (2010). Actualidad, humor y entretenimiento en los programas de televisión: de la terminología a la realidad profesional. Trípodos, 27, 59-73. Recuperado de https://www.raco.cat/index.php/Tripodos/article/view/234157/316371

Silverstone, R. (2007). Media and Morality: On the Rise of the Mediapolis. Cambridge: Polity.

Simancas, E. y González-Pavón, A. (2017): Análisis del discurso político televisivo en España: Politainment y Storytelling. En F. J. Herrero Gutiérrez y C. Mateos Martín (Coord.), Del verbo al bit (pp. 11581176). La Laguna: Sociedad Latina de Comunicación Social.

Soler, T. (2013). Una pareja de hecho. En M. Redondo y Campos-Domínguez, E. (2015). Implicaciones éticas del infoentretenimiento televisivo. Comunicació: Revista de Recerca i dÀnàlisi, 32, 73-89. doi: $10.2436 / 20.3008 .01 .130$

Suárez-Ortega, M. (2005). El grupo de discusión. Una herramienta para la investigación cualitativa. Barcelona: Laertes Educación.

Teso, G. y Piñuel, J. L. (2015). Multitarea, Multipantalla y Práctica social del consumo de Medios entre los jóvenes de 16 a 29 años en España. En M. J. Arrojo y J. L. Piñuel (Coord.), Contenidos digitales y multipantalla (pp. 93-107). La Laguna: Sociedad Latina de Comunicación Social. 
Toffler, A. (1980). The Third Wave. En S. Berrocal, E. Campos-Domínguez y M. Redondo (2014). Prosumidores mediáticos en la comunicación política: El «politainment» en YouTube. Comunicar, (43), 65-71. doi: 10.3916/C43-2014-06

Wengraf, T. (2001). Qualitative Research Interviewing. Biographic, narrative and semistructured methods. Londres: Sage.

Wilson, J. (2011). Playing with politics: Political fans and Twitter faking in post-broadcast democracy. Convergence, 17(4), 1-17. doi: 10.1177/1354856511414348

\section{Notas}

${ }^{1}$ Doctorado de Educación y Comunicación social. I Plan de Investigación y Transferencia de la Universidad de Málaga.

Este trabajo de investigación se desarrolla en el marco del Proyecto de I+D CSO2017-85483-R “JUVEN-TV. Nuevos consumos frente a viejos estereotipos: análisis de la recepción por parte de la juventud española de sus representaciones televisivas actuales", financiado por el Ministerio de Ciencia, Innovacioìn y Universidades del Gobierno de España. 